https://doi.org/10.11646/palaeoentomology.4.4.1

http://zoobank.org/urn:1sid:zoobank.org:pub:355BF7D2-44AD-44C3-9074-3DC4D4BD5D00

\title{
Looking back at the latest 20 years
}

\author{
EWA KRZEMIŃSKA \& WIESŁAW KRZEMIŃSKI \\ Institute of Systematics and Evolution of Animals, Polish Academy of Sciences, Stawkowska 17, PL31-016, Kraków, Poland \\ झ"krzeminska@isez.pan.krakow.pl; @ https://orcid.org/0000-0002-3431-9963 \\ ”"krzeminska@isez.pan.krakow.pl; ○ https://orcid.org/0000-0001-5685-891X
}

Twenty years ago the International Palaeoentomological Society was founded in Kraków during the $2^{\text {nd }}$ Congress on Palaeoentomology $\left(5^{\text {th }}-9^{\text {th }}\right.$ September, 2001). This congress was preceded by a world conference in Moscow, 1998 (which was afterwards given the formal numbering as first), and World Congress on Amber Inclusions in Vitoria-Gasteiz, Basque Country, Spain, 1998. Later, Brazilian Symposium on Palaeoarthropodology in Ribeirão Preto, Brazil held for the first time in 2000, took place. The event in Kraków attracted a record number of 120 participants. We were quite aware that this frequency in 2001 was partially caused by the curiosity of the country which for long time was behind the iron curtain. Literally most of the countries were represented; from USA to China, from Russia to South Africa, as you may notice from the list of 53 founding members, below, who also provided the starting Society with first donations.

List of founding members (in alphabetical order): Jörg Ansorge-Germany; Bruce Archibald-USA; Dany Azar-Lebanon; Carsten Brauckmann-Germany; Denis J. Brothers-South Africa; Robert CoramUnited Kingdom; Emma Deboise-United Kingdom; Torsten Dikow-USA; Robert Dudley-USA; Stefan Dwillies-Germany; Peter Ernst-Germany; Andrei Gorochov—Russia; Elke Groening-Germany; Fabian Haas-Germany; Jean-Paul Haenni-Switzerland; Joseph Hannibal-USA; Aleksander Herczek-Poland; Christel Hoffeins - Germany; Hans Werner HoffeinsGermany; Edmund A. Jarzembowski-United Kingdom; Rolf Kohring $\dagger$-Germany; Jan Koteja $\uparrow$-Poland; Ewa Krzemińska-Poland; Wiesław Krzemiński-Poland; Daniel Kubisz-Poland; Janusz Kupryjanowicz-Poland; Conrad C. Labandeira-USA; Osvaldo LovisoloItaly; Sara Lubkin-USA; Elena D. LukashevichRussia; Rafael Gioia Martins-Neto $\uparrow$-Argentina; Karin Nordmann-Ernst-Denmark; Evgeny E. PerkovskiUkraine; Julian F. Petrulevicius-Argentina; Yuri A. Popov $\dagger$-Russia; Jakub Prokop—Czech Republic; Dong Ren —China; Andrew J. Ross — United Kingdom; Dimitri Shcherbakov—Russia; Thomas Schlüter-Kenya; NinaD.
Sinichenkova—Russia; Elżbieta Sontag—Poland; Adam Stroiński-Poland; Ryszard Szadziewski—Poland; Jacek Szwedo-Poland; Przemysław Trojan $\uparrow$-Poland; Wanda Weiner-Poland; Wolfgang Weitschat - Germany; Piotr Węgierek-Poland; Wilfried Wichard-Germany; Robin J. Wootton-United Kingdom; Jörg WunderlichGermany; Vladimir V. Zherikhin $\uparrow$-Russia.

Alexandr P. Rasnitsyn became the first president. Further on, next presidents were elected from among the organisers of subsequent conferences. Each of these meetings was an unforgettable event, as the organisers conceptualised them in a manner that we could visit the most exciting palaeoentomological sites in their countries. And so we visited (Fig. 1):
$3^{\text {rd }}$ Congress in 2005, Pretoria, South Africa: so very exotic country to most of us. We visited the Karoo Plateau with its Permian localities known of first land vertebrates. Among rich Gondwanan vegetation, colorful and large flowers of Protea (an ancient angiosperm) were just blooming. In Pretoria the Fossils X3 (congress on Fossil Insects, Arthropods and Amber) was initiated by merging three related congresses.
$4^{\text {th }}$ Congress in 2007, Alava (Vitoria-Gasteiz), Basque Country, Spain: we visited the protected localities of Alava amber. The annual journal of the Society, Alavesia, was founded there by the Museo de Ciencias Naturales de Álava and was active for three years (for earlier trials of establishing the journal of the Society prior to the bimensual Palaeoentomology see the editorial by Jacek Szwedo).
$5^{\text {th }}$ Congress in 2010, Beijing, China: a long trip to Daohugou and other Jurassic localities, not as famous then as they are today. Historical monuments, among them the Forbidden City and Great Wall: for many of us it was the first and only chance to visit them.
$6^{\text {th }}$ Congress in 2013, Byblos, Lebanon: we had the chance to see the Lebanese amber outcrops of Hammana and Jezzine, as well as Jurassic amber in natural sediments. Ancient Byblos was explored in heavy rain that did not cease all day!
$7^{\text {th }}$ Congress in 2016, Edinburgh, Scotland: impressive $30 \mathrm{~m}$ high cliffs over the beach in Burnmouth showing exposed non-marine profiles from the late Devonian to early Carboniferous. The famous Rhynie locality: probably most of us still have the piece of Devonian chert offered as a gift; has anyone tried to slice it? 

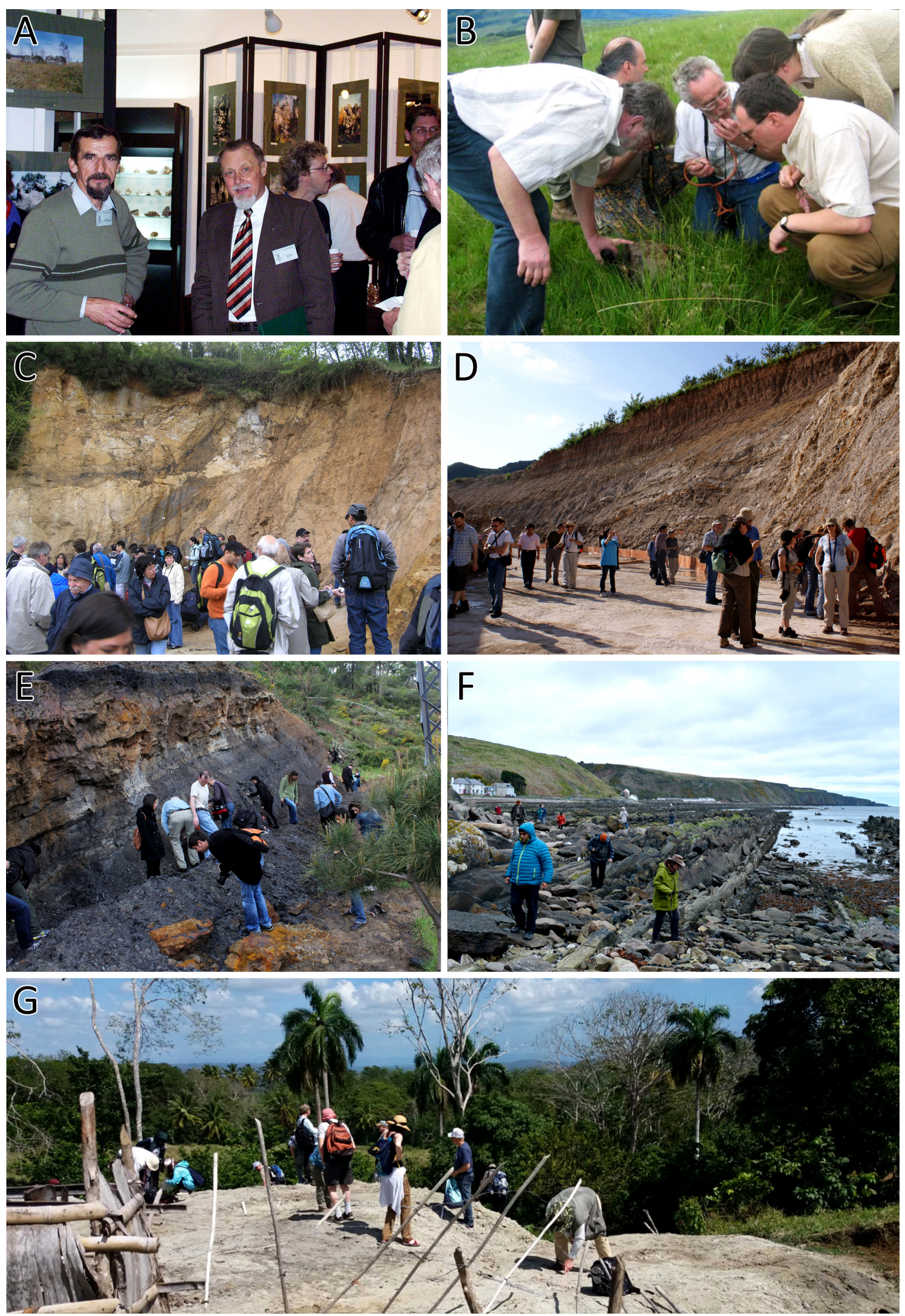

FIGURE 1. Memories. A, Kraków, Poland, 2001; Ryszard Szadziewski and Przemysław Trojan in a photography exhibition during the congress. B, Pretoria, South Africa, 2005; excursion to Drakenberg Mountains, foreground from left: Yuri Popov, Alex Rasnitsyn (centre) and Jörg Ansorge. C, Alava, Spain, 2007; visit to Peñacerrada amber bearing site of Alava. D, Beijing, China, 2010; excursion to Daohugou fossil insects outcrop. E, Byblos, Lebanon, 2013; excursion to Roum - Aazour - Homsiyyeh amber outcrop. F, Edinburgh, Scotland, 2016; excursion to the beach at Burnmouth (photo: Y. Candela). G, Santo Domingo, Dominican Republic, 2019; visit to a Dominican amber mine. 
$8^{\text {th }}$ Congress in 2019, Santo Domingo, Dominican Republic: unforgettable mines of Dominican amber, 'waste' heaps that were not all waste.

Looking back at these 20 years, what major changes in our approach to fossil insects occurred in meantime? Comparing the publications from before 20 years and now we see a growing share of taxa described from amber inclusions. Fossil resins with embedded insects are now available in great numbers from various continents and epochs. These perfectly preserved specimens enable us comparisons with recent fauna at the species level, beginning from the Cretaceous. We became aware that the clue to fossil fauna is the Recent fauna. As a consequence, the phylogenies that include both fossil and Recent species became feasible, and nowadays are a must in submissions to most high-impact journals.

However, the sediment fossils will always remain invaluable as the witnesses of times and locations which insectiferous amber do not offer. Here, the Carboniferous to Miocene localities in China should be mentioned at first place; their value has been recognised in the course of latest 20 years. Several members of our Society have participated in these studies working at place with Chinese colleagues. A large team of palaeoentomologists have also collaborated on the Eocene Insect Limestone of the Bembridge Marls in the Isle of Wight, UK. The Lower Cretaceous Crato Formation (Brazil), the next important Konservat-Lagerstätten, has attracted general attention.

Some crucial questions raised 20 years ago, are always not yet answered and still waiting for fresh data and young minds, like (among many) the age and duration of Baltic amber; as well as its botanical origin. Other question is the origin of insect flight: during the congress in Kraków, an entire session was devoted to the flight origin, and seeing the convincing movies of stone flies and mayflies rowing and sailing with their wings in water some of us were sure we are close to capture the problem. However, rather unexpectedly the idea met much criticism. Further investigations concentrated on the identification of limbs from which the wings could originate, and the genetic background of their development. And what about the selective pressure which caused transformation of the thorax and development of muscular and nervous systems? What purpose could these proto-wings have served before they could fly?

Certainly each of us has in mind other unsolved questions. May the upcoming years bring the answers and open up new exciting questions, and may you find help in the company of your friends and colleagues of the Society. 